\title{
Hardness inhomogeneity and local strengthening mechanisms of an Al1050 aluminium alloy after 1 pass of equal channel angular pressing
}

\author{
X.G. Qiao, M.J. Starink, N. Gao \\ Materials Research Group, School of Engineering Sciences, University of \\ Southampton, Southampton SO171BJ, UK
}

\begin{abstract}
Samples of an A11050 aluminum alloy $(99.5 \% \mathrm{Al})$ were subjected to equal channel angular pressing (ECAP) at room temperature for 1 pass. The microhardness is highest at the centre of the cross section of the billet, and the grain size is smallest at the edges, which rules out grain size strengthening as the dominant hardening mechanism. On isochronal ageing at temperatures between 200 and $375{ }^{\circ} \mathrm{C}$, low angle grain boundaries disappear, the hardness gradually decreases, and hardness differences gradually disappear. A model is described that captures the strengthening mechanisms and model results fit the experimental results well. Analysis of recovery behaviour and strength modelling indicates that the contribution of the dislocations to the strength is higher than that of grain size.
\end{abstract}

Key words: Aluminium; Equal channel angular pressing (ECAP); Strength model, Dislocation density; Grain size.

\section{Introduction}

Equal channel angular (ECA) pressing is the most well known processing method among the group of severe plastic deformation (SPD) methods [1]. ECAP can be performed on a single specimen repeatedly because the specimen's cross section shape does not change after ECAP, and through repeated ECAP accumulated plastic strains in the order of 10 can be achieved. Through ECAP, conventional microstructures of metallic alloys are changed to ultrafine-grained ones [2]. Materials with submicron- or nano-scaled grains produced by ECAP are low porosity, low oxide content and safe compared with the counterparts by gas condensation and mechanical alloying $[1,3]$.

The local microstructure and mechanical properties of aluminium alloys processed by equal channel angular pressing (ECAP) have been studied extensively since the invention of this technique $[4,5]$. But the relationship between the inhomogeneous microstructure and mechanical properties after ECAP is still not clear. Especially, there are few reports on how the enhanced strength of aluminium after ECAP is quantitatively related to dislocation density and grain size. Aluminium experiences a severe deformation during ECAP that leads to a high strength with a high density of dislocation and a significantly decreased grain size. It is often suggested that the enhanced yield strength of aluminium alloys after ECAP is due to the refined grains, with the contribution of dislocation density receiving little mention. In present 
investigation, microhardness testing was carried out on the cross section of ECAPprocessed billet to measure the microhardness distribution over the cross section. To facilitate the identification of the contribution of dislocation density to the yield strength, a series of heat treatments were performed on the ECAP-processed billets to lower the dislocation density through recovery with minor grain size changes. The microstructure of the interested area was observed with the objective of determining the relationship between the nonuniform microhardness and the local microstructure.

\section{Experimental procedure}

This study was carried out on a commercial Al1050 aluminium alloy (approximate composition $\mathrm{Al}-0.25 \mathrm{Fe}-0.15 \mathrm{Si}$ (in wt. \%) with further minor impurities) supplied as an extruded rod of $4 \mathrm{~m}$ length and $9.53 \mathrm{~mm}$ diameter. Prior to ECAP, the rod was cut to cylindrical ECAP billets of $65 \mathrm{~mm}$ length. These billets were pressed in an equal-channel angular die of $9.7 \mathrm{~mm}$ diameter channel, with a $90^{\circ}$ channel intersection angle $(\Phi)$ and a $20^{\circ}$ curvature on the outer side of channel intersection ( $\Psi$ ) (Fig. 1). Specimens were lubricated with a suspension of $\mathrm{MoS}_{2}$ in mineral oil ('ASO oil' supplied by Rocol) in order to reduce the friction between the plunger, specimen and the die. A careful alignment of the plunger and upper channel of the die was carried out. A plunger pushing speed of $0.5 \mathrm{~mm} / \mathrm{s}$ was employed. After one pass of ECAP, another specimen was put in the die to push out the first specimen. The ECAP process was conducted at room temperature for 1 pass. The equivalent strain is about 1. To study recovery behaviour, ECAP-processed billets were annealed for $0.5 \mathrm{~h}$ at $200{ }^{\circ} \mathrm{C}, 250{ }^{\circ} \mathrm{C}, 275^{\circ} \mathrm{C}, 300{ }^{\circ} \mathrm{C}, 325^{\circ} \mathrm{C}, 350{ }^{\circ} \mathrm{C}$ and $375{ }^{\circ} \mathrm{C}$, respectively.

\section{Cross section}
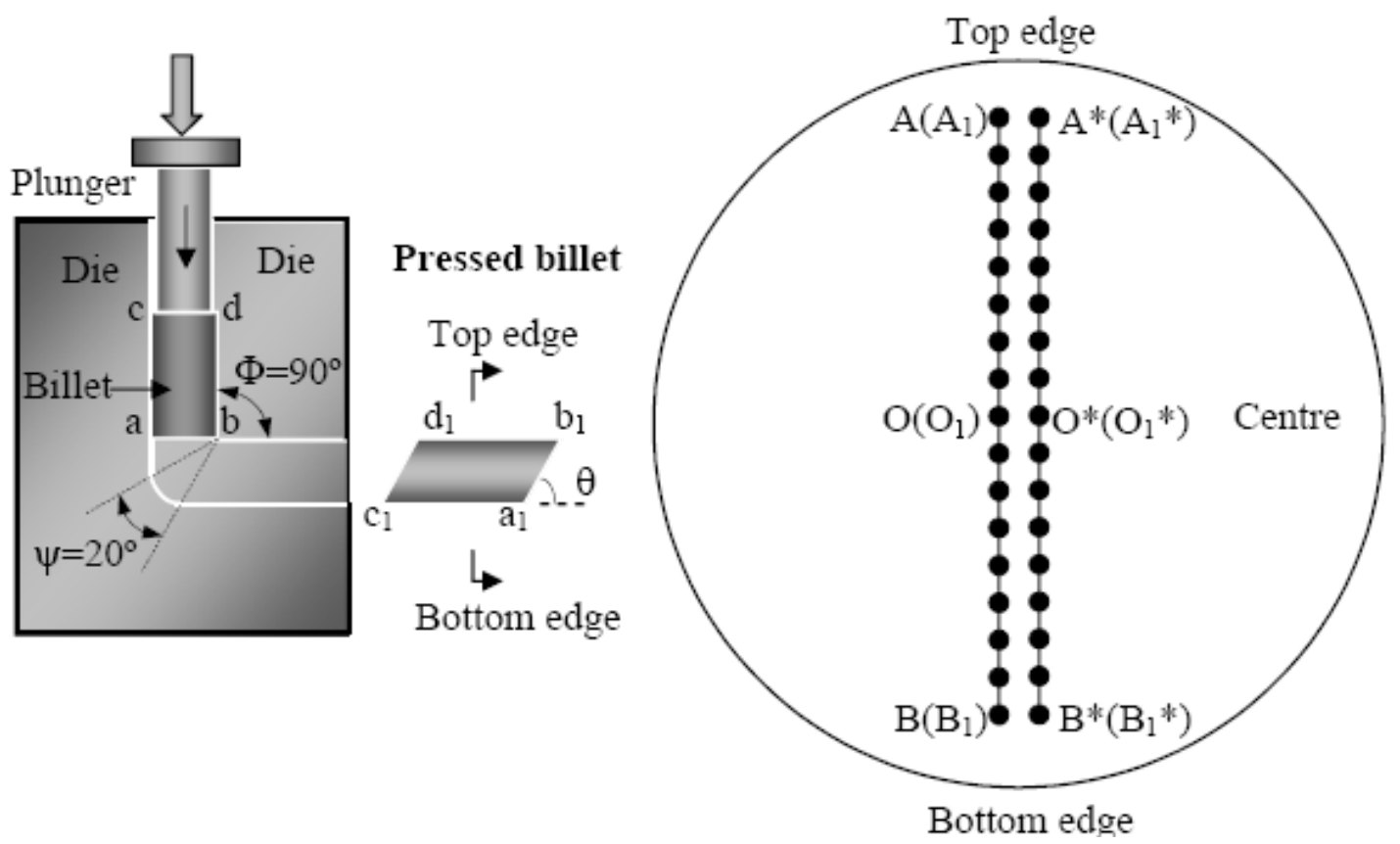

Fig. 1 Schematic illustration of cross section of the ECAP-processed billet for microhardness measurement. 
Samples of $2 \mathrm{~mm}$ thickness were machined from ECAP-processed billets and heat treated billets along the longitudinal direction for micro hardness testing. The circular surface was ground by abrasive papers from 600 grits to 1200 grits. Micro hardness testing was carried out on the circular surface. As shown in Fig. 1, individual values of the microhardness were measured on two lines across the diameter of the circular surface from top to bottom in an incremental step of $0.5 \mathrm{~mm}$. The distance between two lines is $0.5 \mathrm{~mm}$ and the endpoints of both two lines are $0.75 \mathrm{~mm}$ to the sample edge. The indentations were removed by grinding and polishing after the hardness values of every point were measured. The values were marked as $A, A^{*}, B$ and $B^{*}$ etc. The second hardness measurement was carried out at the same positions with the first measurement. The values were marked as $A_{1}, A_{1}{ }^{*}, B_{1}$ and $B_{1}{ }^{*}$ etc. The hardness of each point was calculated through averaging the measurements of four individual indentations on the equivalent locations. For instance, the hardness at point $\mathrm{A}$ was calculated by averaging the hardness obtained from indentation at the equivalent positions $\mathrm{A}, \mathrm{A}^{*}, \mathrm{~A}_{1}$ and $\mathrm{A}_{1}{ }^{*}$. Micro hardness was tested on an MHT-1 model micro Vickers hardness tester. A force of $300 \mathrm{~g}$ was applied on all the samples except for the softer $350{ }^{\circ} \mathrm{C}$ and $375{ }^{\circ} \mathrm{C}$ heat treated samples, where a $100 \mathrm{~g}$ load was applied. Holding time is 15 second for all hardness testing.

Electron backscattered diffraction (EBSD) was used to characterize the microstructure as well as grain and subgrain boundary misorientation distribution in both ECAPprocessed billets and heat treated billets. Samples of $10 \mathrm{~mm}$ length used for EBSD analysis were machined from the middle of ECAP-processed billets. For sample preparation, the surface of cross section was first mechanically ground up to 4000-grit $\mathrm{SiC}$ paper, then electropolished employing an electrolyte composed of $33 \mathrm{vol} \%$ nitric acid and 67 vol\% methanol. The electropolishing was carried out with a DC voltage of 20-30 V for 30 seconds. The electrolyte was cooled to and maintained at a temperature of $-30{ }^{\circ} \mathrm{C}$ using liquid nitrogen. The equipment used was a JEOL JSM6500F thermal field emission gun scanning electron microscope (FEG-SEM) equipped with an HKL EBSD detector and HKL Channel 5 software. The SEM accelerating voltage was set to $15 \mathrm{kV}$. Step size was $1 \mu \mathrm{m}$. An orientation imaging microscopy (OIM) map was obtained from the cross section perpendicular to the longitudinal direction of ECAP-processed billets. The position of EBSD analysis were marked as A, O and B (see Fig. 1). For misorientation angle distributions the lowest cut off angle was set about $0.5^{\circ}$ higher than the angle at which an apparent drastic increase in boundary angle density occurs. This apparent increase is due to local deformation and noise, and is thus eliminated from the experiments.

\section{Results}

\subsection{Microhardness of the ECAP-processed billet}

The microhardness distribution on the cross section of the ECAP-processed billet (as defined in Fig. 1) is shown in Fig. 2. The error bars in the figure define a symmetrical confidence interval by plus-minus standard deviation. (The reported standard deviations refer to the standard deviations obtained from 4 indentations for each data 
point. Hence measurement accuracy of the mean is a factor 2 better.) The average microhardness of the as pressed billet on the top edge $(0.75 \mathrm{~mm}$ to the edge) is $42 \pm$ 1.2 Hv while the counterpart on the bottom edge is $39 \pm 4.2 \mathrm{Hv}$. The microhardness increases on approaching the center, where the average microhardness is $48 \pm 1.4 \mathrm{Hv}$.

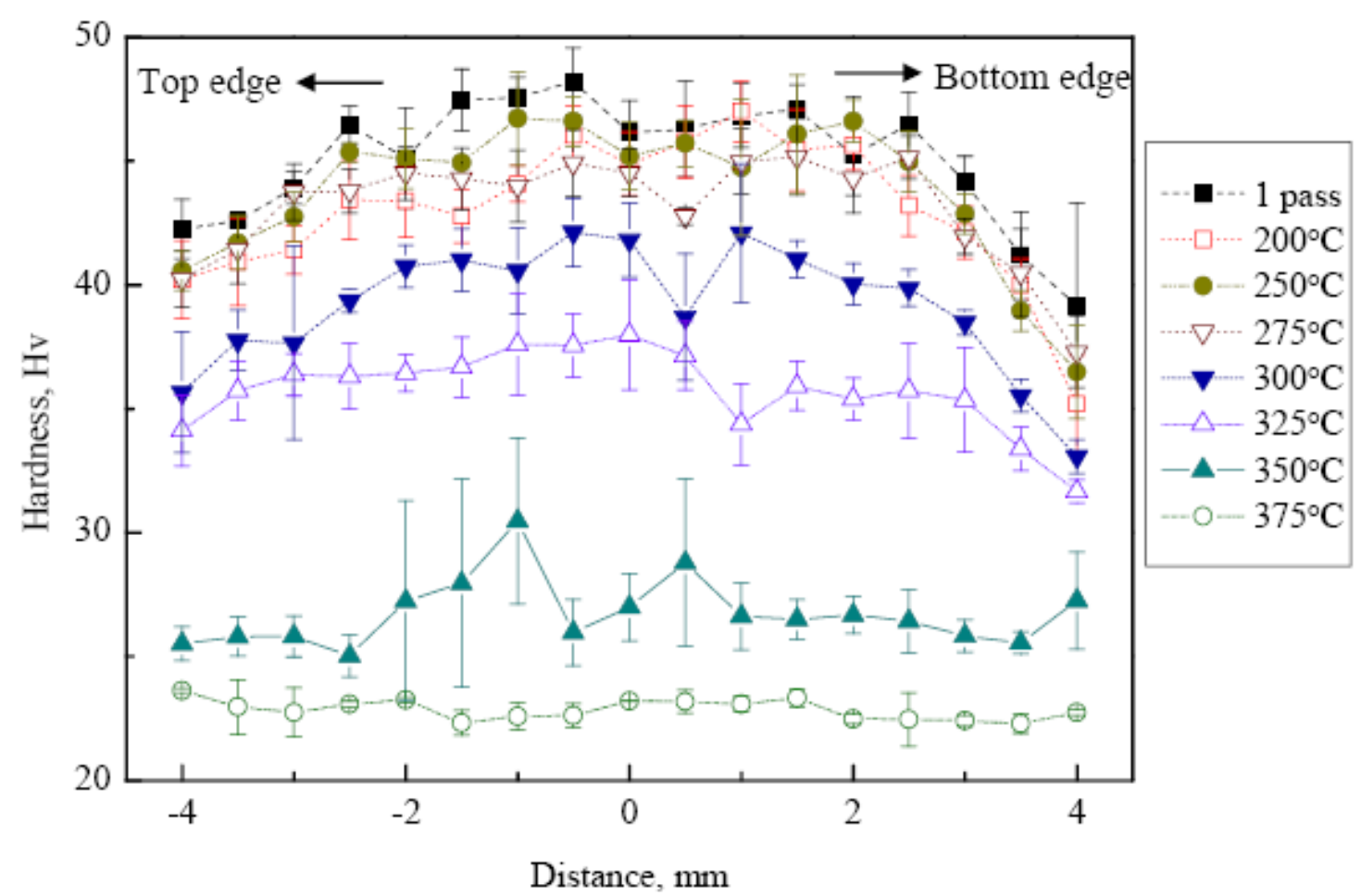

Fig. 2 The average microhardness distribution over the cross section from the top edge to the bottom edge of the ECAP-processed billet and the heat treated billet.

\subsection{Microstructure of the ECAP-processed billet by EBSD}

To investigate the origins of the variation of the microhardness across the circular surface, microstructure at the top edge (Mark A), the center (Mark O) and the bottom edge (Mark B) on the circular surface of the ECAP-processed billet has been observed by EBSD. Fig. 3 a), c) and e) show the OIM maps of the top edge, the centre and the bottom edge of the ECAP-processed billet. Dark thick lines are used to represent grain boundaries of which the misorientation angle is greater than $15^{\circ}$. The grey fine lines represent subgrain boundaries of which the misorientation angle is smaller than $15^{\circ}$ and greater than $4^{\circ}$. Misorientations less than $4^{\circ}$ were ignored in order to remove noise. The average grain sizes at the top edge, the center and the bottom edge, as calculated by the mean linear intercept method, are $8.2 \mu \mathrm{m}, 26 \mu \mathrm{m}$ and $19 \mu \mathrm{m}$.

After 1 pass of ECAP, a large amount of subgrains with low angle grain boundaries (LAGB) appears in the original coarse grains due to the severe strain at the intersection corner of the die. Fig. 4 a), c) and e) show the misorientation distribution of the top edge, the centre and the bottom edge. The fraction of LAGB is $47 \%$ at the top edge, $75 \%$ at the centre and $73 \%$ at the bottom edge. 
It is worth noting that among the three positions the centre has the highest hardness, whilst also the grain size is largest at this location. Hence, grain boundary strengthening is not the dominant strengthening mechanism. Conventional strengthening mechanisms can further include solid solution strengthening, precipitation/dispersion strengthening, dislocation strengthening and grain boundary strengthening. In the current study, the composition of Al1050 is close to pure aluminium and the microhardness difference occurs in the same billet so that the solid solution strengthening and precipitation/dispersion strengthening are not significant.

In order to identify the dislocation hardening contribution to the difference of microhardness among the top edge, the centre and the bottom edge of the circular surface, a series of recovery heat treatments were carried out to decrease the dislocation density with limited grain size changes.

\subsection{Microstructure of the heat treated billet}

Fig. 3 b), d) and f) show the OIM microstructure of the top edge (Mark A), the center (Mark O) and the bottom edge (Mark B) on the circular cross section surface of the billet heat treated for $0.5 \mathrm{~h}$ at $350{ }^{\circ} \mathrm{C}$. The average grain sizes at the top edge, the center and the bottom edge are $21 \mu \mathrm{m}, 12 \mu \mathrm{m}$ and $11 \mu \mathrm{m}$, respectively. The grain size at the centre and the bottom edge decreased after annealing due to the recrystallization in the billet processed by ECAP. The high density of dislocations in the ECAPprocessed billets, and the related high stored energy, caused recrystallization during annealing. The recrystallization has not fully completed and some subgrain boundaries and wavy grain boundaries can still be seen in Fig. $3 \mathrm{~d}$ ) and f). However, the grain size at the top edge increased slightly after annealing at $350{ }^{\circ} \mathrm{C}$ due to the recrystallization and the grain growth.

Fig. 4 b), d) and f) show the grain boundary misorientation angle distribution at the three locations for the pressed and heat treated $0.5 \mathrm{~h}$ at $350{ }^{\circ} \mathrm{C}$ sample. Heat treating at $350{ }^{\circ} \mathrm{C}$ for $0.5 \mathrm{~h}$ causes a drastic reduction in LAGB. The fraction of LAGB is $17 \%$ at the top edge, $17 \%$ at the centre and $18 \%$ at the bottom edge.

\subsection{Microhardness of the heat treated billet}

Fig. 2 also includes the microhardness distribution on the circular cross section surface of ECAP-processed billets after annealing at various temperatures. With increasing annealing temperature, the microhardness at each position decreases and the difference in average hardness between locations reduces. For example, after annealing at $350{ }^{\circ} \mathrm{C}$, the average microhardness of the top edge, the centre and the bottom edge are close together at $25.5 \mathrm{Hv}, 27.0 \mathrm{Hv}$ and $27.3 \mathrm{Hv}$, respectively. However, the variation in hardness for equivalent positions as measured by the standard deviation appears to increase with heat treatment temperature up to $350{ }^{\circ} \mathrm{C}$. The reduction in difference in microhardness among the top edge, the centre and the bottom edge after heat treatment is due to recovery and recrystallization [6]. The deviation of the individual hardness value at equivalent positions, as reflected in the standard deviation in Fig. 2 can be explained by a partially recrystallized 
microstructure (see Fig. 3 b), d) and f)). When measuring hardness through multiple microhardness indentations (four in this study), the individual hardness value will be slightly higher when measured on the unrecrystallized area; and slightly lower when measured on the recrystallized area. This effect causes a rise in the standard deviation between the hardness values for the equivalent points.

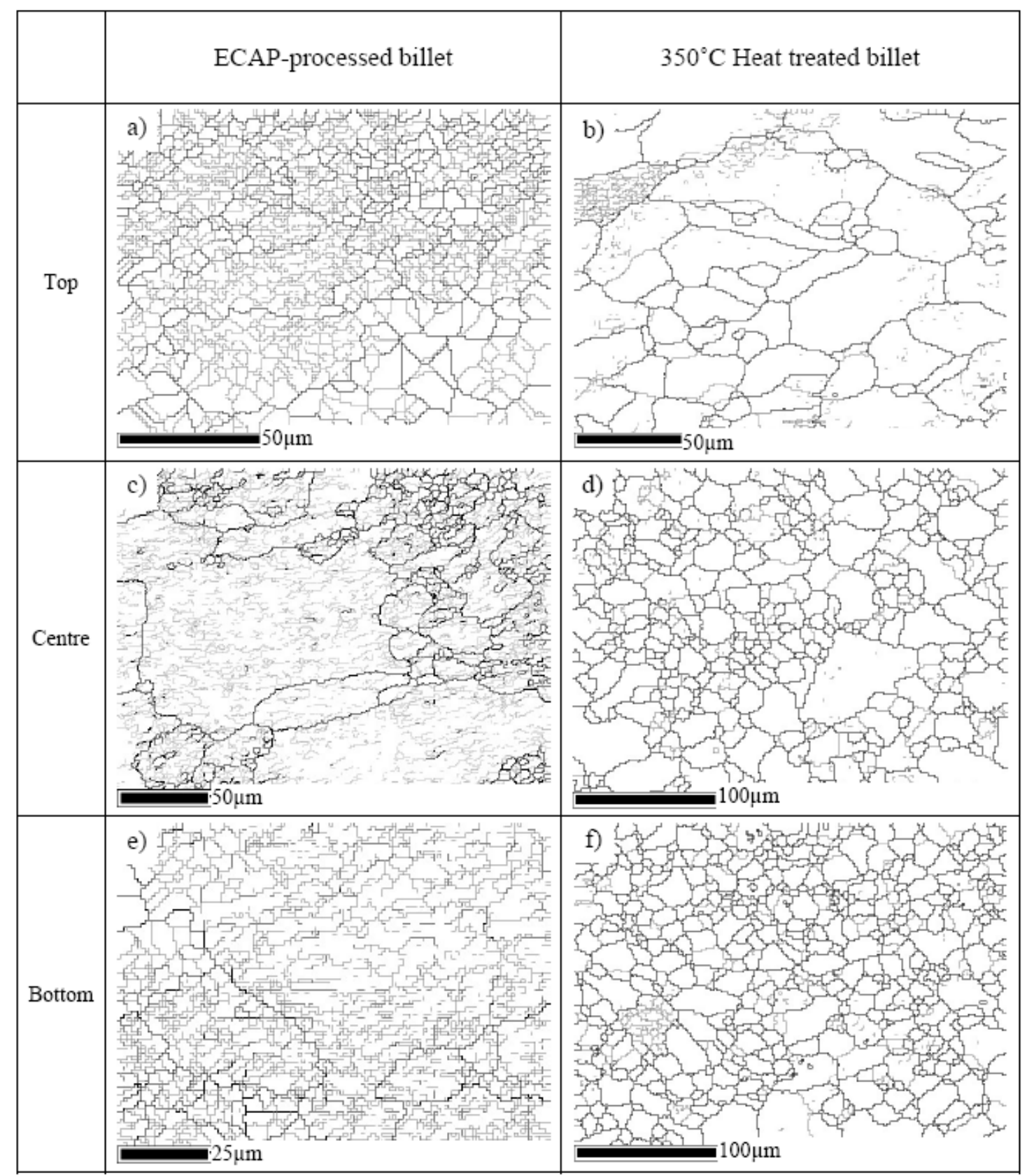

Fig. 3 The OIM map of the billet cross section at the top edge ( $a$ and $b$ ), the centre (c and $\mathrm{d}$ ) and the bottom edge (e and f). a, c and e are from the ECAP-processed billet; $b$, $\mathrm{d}$ and $\mathrm{f}$ are from the $350{ }^{\circ} \mathrm{C}$ heat treated billet. 


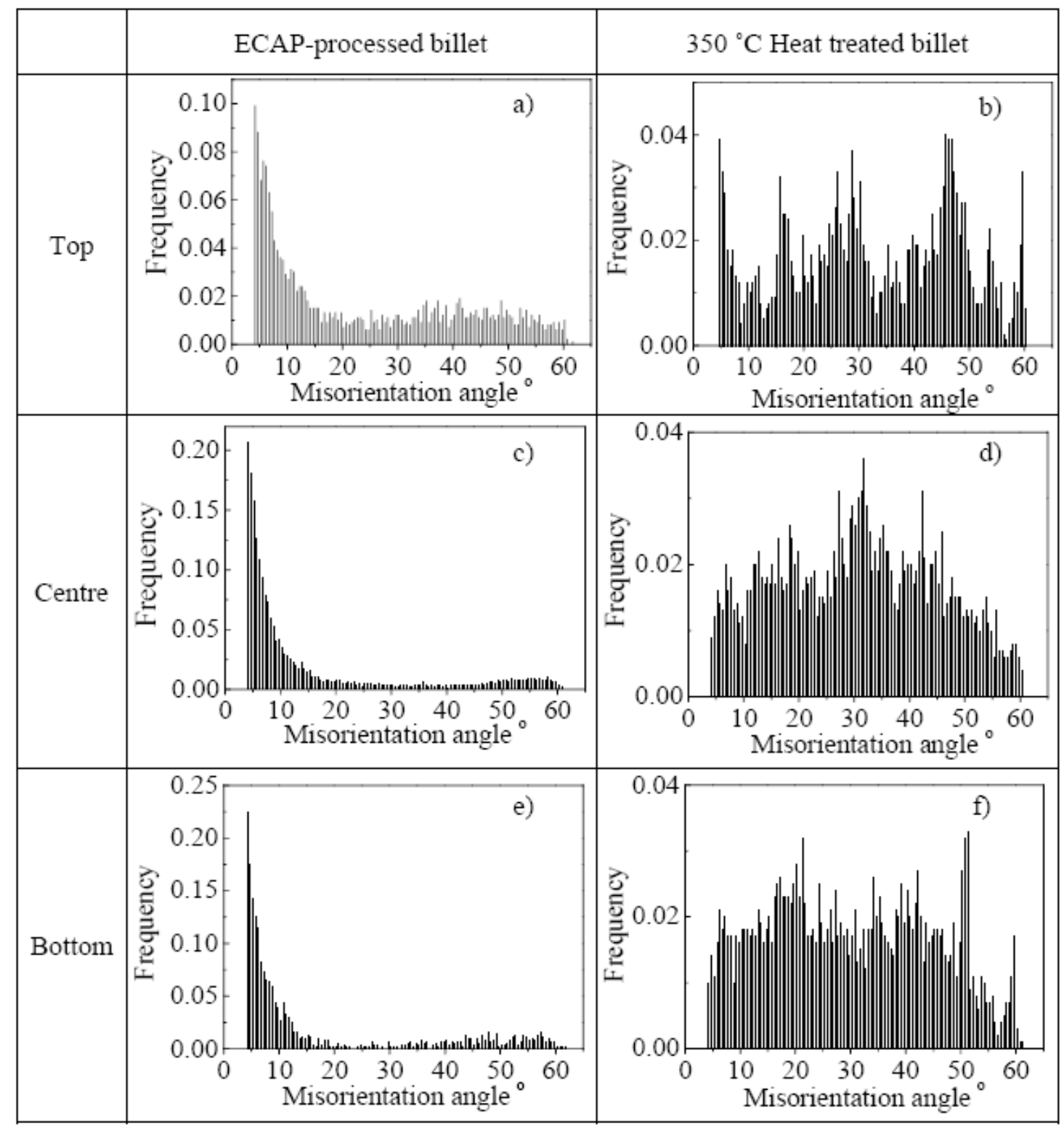

Fig. 4 Misorientation distribution of the ECAP-processed billet (a, c, e) and $350{ }^{\circ} \mathrm{C}$ heat treated billet $(b, d, f)$ at the top edge $(a, b)$, the centre $(c, d)$ and the bottom edge $(e, f)$.

\section{Discussion}

\subsection{Strengthening mechanism of the ECAP-processed aluminum}

During ECAP the strain experienced by billet is homogeneous throughout most of the billet, but the billet experiences an inhomogeneous strain at the corner of the die, which has been revealed by experiment [7,8] and modeling [9]. The deformation in the middle of the billet is generally thought to follow the single shear model while the deformation in both the top edge and the bottom edge are more complex, being influenced by friction, back pressure and channel intersection angle $[1,3]$. The uneven 
deformation inevitably leads to inhomogeneous microstructure and strength of the billet after ECAP. After 1 pass of ECAP, the microhardness of the billet centre is higher than that of the bottom edge and the top edge while the grain size of the billet centre is bigger than that of the bottom edge and the top edge as well.

To analyse strength variations in the present A11050 alloy, it is first noted that the yield strength of fully annealed Al1050 (28 MPa, see [10]) is about $18 \mathrm{MPa}$ higher than that of pure Al. The limited strength of Al1050 is mostly due to solution strengthening (from the limited amount of dissolved elements) and strengthening due to a limited amount of hard intermetallic particles (mostly $\mathrm{Si}$ and $\mathrm{Fe}$ containing phases). These two strengthening contributions are very small and will not significantly vary through the present ECAP and heat treatment. Thus strength variation should be due to variations in grain boundary strengthening and dislocation strengthening. Hence our hardness results and analysis suggests that the uneven deformation results in the dislocation density of the centre being higher than that of the edge. The heat treatment experiments support this hypothesis. After annealing at $350{ }^{\circ} \mathrm{C}$ for $0.5 \mathrm{~h}$, the microhardness of the center is close to that at the edges because the dislocation density difference between the center and the edges has been removed during the heat treatment with limited grain size changes because of the recrystallization.

\subsection{A model of hardness/strength of the ECAP-processed aluminium}

According to a general strength model for polycrystalline Al alloys, the yield strength is given by the following equation $[11,12]$ :

$$
\sigma_{\mathrm{y}}=\Delta \sigma_{\mathrm{gb}}+M \tau_{\text {tot }}
$$

where $\sigma_{\mathrm{y}}$ is yield strength, $\Delta \sigma_{\mathrm{gb}}$ is the strengthening due to the presence of grain or subgrain boundaries, $M$ is a factor often referred to as the Taylor factor and $\tau_{\text {tot }}$ is critical resolved shear stress (CRSS). Contributions to $\tau_{\text {tot }}$ include intrinsic CRSS, solid solution strengthening, strengthening by dislocations inside the grains and precipitation strengthening. For the present alloy, only intrinsic CRSS and dislocations inside grain are main contributions to CRSS because of the low solid solubility of alloying elements and absence of precipitates. The contribution to the yield strength by intrinsic CRSS, solid solution strengthening and precipitation strengthening are taken as a constant term $\sigma_{0}$ because they are virtually constant compared with the contribution of grain size and dislocation density during ECAP and heat treatment. Therefore, the Equation (1) can be written as:

$$
\sigma_{\mathrm{y}}=\Delta \sigma_{\mathrm{gb}}+\sigma_{0}+M \tau_{\mathrm{d}}
$$

$\sigma_{0}$ is taken as $28 \mathrm{MPa}$, which is the yield strength of fully annealed Al1050 [10]. $\tau_{\mathrm{d}}$ is the strengthening by dislocations inside the grains. 
The grain boundary strengthening contribution consists of subgrain boundary strengthening and grain boundary strengthening two parts. The effect of subgrain boundary to the strength is lower than that of a HAGB. Generally, $\Delta \sigma_{\mathrm{gb}}$ is expressed as a function of grain size [13], and as conventionally processed metals have a very low fraction of LAGBs, the distinction between LAGBs and HAGBs can be neglected. But in the present investigation, a high density of LAGBs was observed in the pressed billets and a substantial proportion of the LAGBs have remained in the heat treated billets (see Fig. 4). Here, we consider that at low misorientation angle, strengthening will decrease with decreasing misorientation angle [14]. This effect is captured through introducing $\lambda$, the ratio of subgrain boundary strengthening contribution to grain boundary strengthening contribution. Following $[13,15]$ it then follows:

$$
\Delta \sigma_{\mathrm{gb}}=\alpha_{2} G b\left[\lambda f_{\mathrm{sub}}\left(\frac{1}{\delta}\right)+\left(1-f_{\mathrm{sub}}\right)\left(\frac{1}{D}\right)\right]
$$

where $\alpha_{2}$ is a constant (equalling 2 see $\operatorname{Ref}$ [15]), $G$ is the shear modulus of $\mathrm{Al}, b$ is the Burgers vector, $\delta$ is the subgrain size, $D$ is the grain size. $f_{\text {sub }}$ is the fraction of LAGB.

We will approximate the dislocation strengthening, $\tau_{\mathrm{d}}$, by considering an averaged dislocation density. The $\tau_{\mathrm{d}}$ can generally be expressed by [16]:

$$
\tau_{\mathrm{d}}=\alpha_{1} G b \sqrt{\rho_{1}}
$$

The dislocation density of the microstructure in the heat treated billet is inhomogeneous due to the partial recrystallization. The recrystallized microstructure has a lower dislocation density while the unrecrystallized one higher. Therefore the dislocation contribution $\tau_{\mathrm{d}}$ of the heat treated billet can be expressed as:

$$
\tau_{d}=\alpha_{1} G b\left[\left(1-f_{\mathrm{Rec}}\right) \sqrt{\rho_{1}}+f_{\mathrm{Rec}} \sqrt{\rho_{2}}\right]
$$

In Equation (4) and (5), $\alpha_{1}$ is a constant (about 0.3 [16]) and $f_{\text {Rec }}$ is the recrystallized volume fraction. $\rho_{1}$ and $\rho_{2}$ are dislocation density in the unrecrystallized grain and recrystallized grain, respectively.

When Equation (2), (3), (4) and (5) are substituted into Equation (1), the yield strength for the ECAP-processed billet and the heat treated billet can be expressed as:

$$
\begin{gathered}
\sigma_{\mathrm{y}}=\sigma_{0}+M \alpha_{1} G b \sqrt{\rho_{1}}+\alpha_{2} G b\left[\lambda f_{\text {Sub }}\left(\frac{1}{\delta}\right)+\left(1-f_{\text {Sub }}\right)\left(\frac{1}{D}\right)\right] \\
\sigma_{\text {y }}=\sigma_{0}+M \alpha_{1} G b\left[\left(1-f_{\text {Rec }}\right) \sqrt{\rho_{1}}+f_{\text {Rec }} \sqrt{\rho_{2}}\right]+\alpha_{2} G b\left[\lambda f_{\text {sub }}\left(\frac{1}{\delta}\right)+\left(1-f_{\text {sub }}\right)\left(\frac{1}{D}\right)\right]
\end{gathered}
$$

In the model, the parameters of $\alpha_{1}, \alpha_{2}, G, b, M$ and $\delta$ are taken as 0.3 [16], 2 [15], 26 $\mathrm{GPa}$ [17], $0.286 \mathrm{~nm}, 2.6$ [18] and $1.3 \mu \mathrm{m}$ [4], respectively. The other parameters in 
Equation (6) and (7) can be obtained from the experimental data on Al1050 presented here (see Table 1). $D$ can be measured from the OIM data (Fig. 3). $f_{\text {sub }}$ can be calculated through misorientation distribution figure (Fig. 4 a), c) and e)). $f_{\text {Rec }}$ in Equation (7) is determined from Fig. 4 b), d) and f) as the area in the OIM map occupied by grains that have no interior low angle grain boundaries.

Dislocation density in the recrystallized grain $\left(\rho_{2}\right)$ is estimated as $1 \times 10^{13} \mathrm{~m}^{-2}$, which is the typical dislocation density of annealed aluminium alloys [6]. Dislocation density in the unrecrystallized grain $\left(\rho_{1}\right)$ is estimated as $4 \times 10^{14} \mathrm{~m}^{-2}$ [19], which is the dislocation density of Al6082 after 1 pass of ECAP at room temperature.

The grain size strengthening mechanism is generally interpreted by pile-up edge dislocations, and the effectiveness of grain boundaries in strengthening will depend on the misorientation angle between them. The stress concentration by the pile-up edge dislocation at the subgrain/grain boundaries leads to the dislocation activated in the neighbouring grain. A smaller misorientation angle between the two grains makes it easier to transfer the dislocation movement to the neighbour grain at the same slip system. So the subgrain boundary strengthening effect is smaller than the grain boundary and the value of $\lambda$ is between 0 and 1 . In the present study, $\lambda$ is estimated as 0.5 . The value of $\lambda$ estimation has a limited influence on the strength modelling results because the experiment results and the following modelling results show the grain size only contributes a very small part to the yield strength. The results of the model calculations are shown in Table 1.

\begin{tabular}{c|c|c|c|c|c|c}
\hline \multirow{2}{*}{ parameter } & \multicolumn{2}{|c|}{ ECAP- processed Al1050 billet } & \multicolumn{3}{c}{$350{ }^{\circ} \mathrm{C}$ heat treated Al1050 billet } \\
\cline { 2 - 7 } & Top edge & Centre & Bottom edge & Top edge & Centre & Bottom edge \\
\hline$\rho_{1}, \times 10^{14} \mathrm{~m}^{-2}$ & 4 & 4 & 4 & 4 & 4 & 4 \\
\hline$\rho_{2}, \times 10^{13} \mathrm{~m}^{-2}$ & & & & 1 & 1 & 1 \\
\hline$f_{\text {sub }}$ & 0.473 & 0.746 & 0.73 & 0.170 & 0.166 & 0.180 \\
\hline$f_{\text {Rec }}$ & & & & 0.759 & 0.688 & 0.723 \\
\hline$\delta, \mu \mathrm{m}$ & 1.3 & 1.3 & 1.3 & 1.3 & 1.3 & 1.3 \\
\hline$D, \mu \mathrm{m}$ & 8.2 & 26 & 19 & 21 & 12 & 11 \\
\hline$\sigma_{0}, \mathrm{MPa}$ & 28 & 28 & 28 & 28 & 28 & 28 \\
\hline$\Delta \sigma_{\mathrm{gb}}, \mathrm{MPa}$ & 3.70 & 4.48 & 4.44 & 1.58 & 2.01 & 2.16 \\
\hline$\tau_{\mathrm{d},} \mathrm{MPa}$ & 39.1 & 39.1 & 39.1 & 13.4 & 17.1 & 16.0 \\
\hline$\sigma_{\mathrm{y}}, \mathrm{MPa}$ & 149.0 & 149.8 & 149.7 & 71.9 & 81.3 & 78.1 \\
\hline $\mathrm{HV}$ & 49.7 & 50.2 & 50.1 & 25.5 & 26.6 & 26.1 \\
\hline $\mathrm{HV}$ & 42.2 & 48.2 & 39.1 & 25.5 & 27.0 & 27.3 \\
\hline exp & & & & & & \\
\hline
\end{tabular}

Table 1 Strength predictions for the ECAP-processed billet and the heat treated billet.

In order to compare the yield strength modelling results and micro hardness test result, the relationship between hardness and yield strength of Al1050 alloy is present in Fig. 5. The solid squares in Fig. 5 are four groups of values of Vickers hardness (HV) and

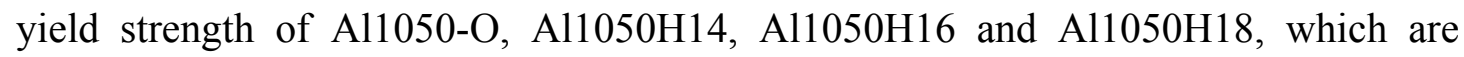
obtained from reference [10] (see Table 2). The Vickers hardness (HV) in Table 2 is 
converted from Brinell hardness $(\mathrm{HB})$ using $\mathrm{HB}=3.76211+0.826368 \mathrm{HV}$ [20]. The curve in Fig. 5 is the fit curve using Boltzmann model. The fit equation and parameters values are also shown in Fig. 5. The hardness calculated from this relationship (HVcal) is listed in Table 1.

The modelling results in Table 1 show a reasonable good correspondence between measured and predicted hardness. This indicates that the present model may form a sound basis for predicting and analysis strength of severe plastically deformed metals. The model indicates that the strength contributed by dislocation density is much higher than the strength contributed by grain size in both ECA press billet and heat treated billet. This is consistent with findings by Gubicza et al [21], who showed that for various severely plastically deformed alloys the yield strength can be predicted well by Eqs 2 and 4, disregarding GB strengthening, for dislocation densities measured through X-ray diffraction line broadening. Comparing the value of $\mathrm{HV}_{\text {exp }}$ and $\mathrm{HV}_{\text {cal }}$ shows the hardness of the heat treated billet achieved by modelling is close to the experimental data, suggesting that the model captures the different strengthening effects well. However, the modelling hardness of the ECAP-processed billet slightly deviates from the experimental hardness. The modelling hardness at the top edge, the centre and the bottom edge are all around $50 \mathrm{Hv}$ while the experimental hardness at those positions is $42 \mathrm{Hv}, 48 \mathrm{Hv}$ and $39 \mathrm{Hv}$. This deviation is because that the same dislocation density $\left(4 \times 10^{14} \mathrm{~m}^{-2}\right)$ was used in Equation (6) to calculate the hardness of the ECAP-processed billet at the top edge, the centre and the bottom edge. The present results indicate that the dislocation density at different areas of the ECAPprocessed billet could be slightly higher or lower than $4 \times 10^{14} \mathrm{~m}^{-2}$ due to the inhomogeneous strain during ECAP.

To verify these suggestions about differences in local dislocation density one might attempt dislocation density measurements through transmission electron microscopy (TEM). However, it should be realized that dislocation density will be inhomogeneous and that accuracy of dislocation density measurement in TEM on severely plastically deformed Al alloys is typically associated with confidence of at best about $\pm 20 \%$ [22]. Hence, it is unlikely that the variations in dislocation density between the different areas can be efficiently detected by TEM, and hence TEM was not attempted.

\begin{tabular}{c|c|c|c}
\hline & HB & HV & Yield strength, MPa \\
\hline Al1050-O & 21 & 20.9 & 28 \\
\hline Al1050-H14 & 30 & 31.8 & 103 \\
\hline Al1050-H16 & 35 & 37.8 & 124 \\
\hline Al1050-H18 & 43 & 47.5 & 145 \\
\hline
\end{tabular}

Table 2 Hardness and yield strength of Al1050 at various states of heat treatments [10]

An alternative model for the strength of ultra-fine grained materials, employed by several researchers $[23,24,25]$, considers the strengthening by LAGBs as due to 
individual dislocation in the grain boundary. The model then considers strengthening to be given by Eq 4 with dislocation density approximated by $1.5 S_{\mathrm{V}} \theta / b$, where $S_{\mathrm{V}}$ is the area of boundaries per unit volume and $\theta$ is the grain boundary misorientation angle [24]. To apply this model we calculated $S_{\mathrm{V}}$ and $\theta$ from our EBSD data. If all dislocations are presumed to be located in the LAGB, the results show a reasonable prediction of hardness, about $15 \%$ higher than the experimental hardness for both ECAP-processed billets and heat treated billets. A comparison study of two models is currently underway and will be published in the future.

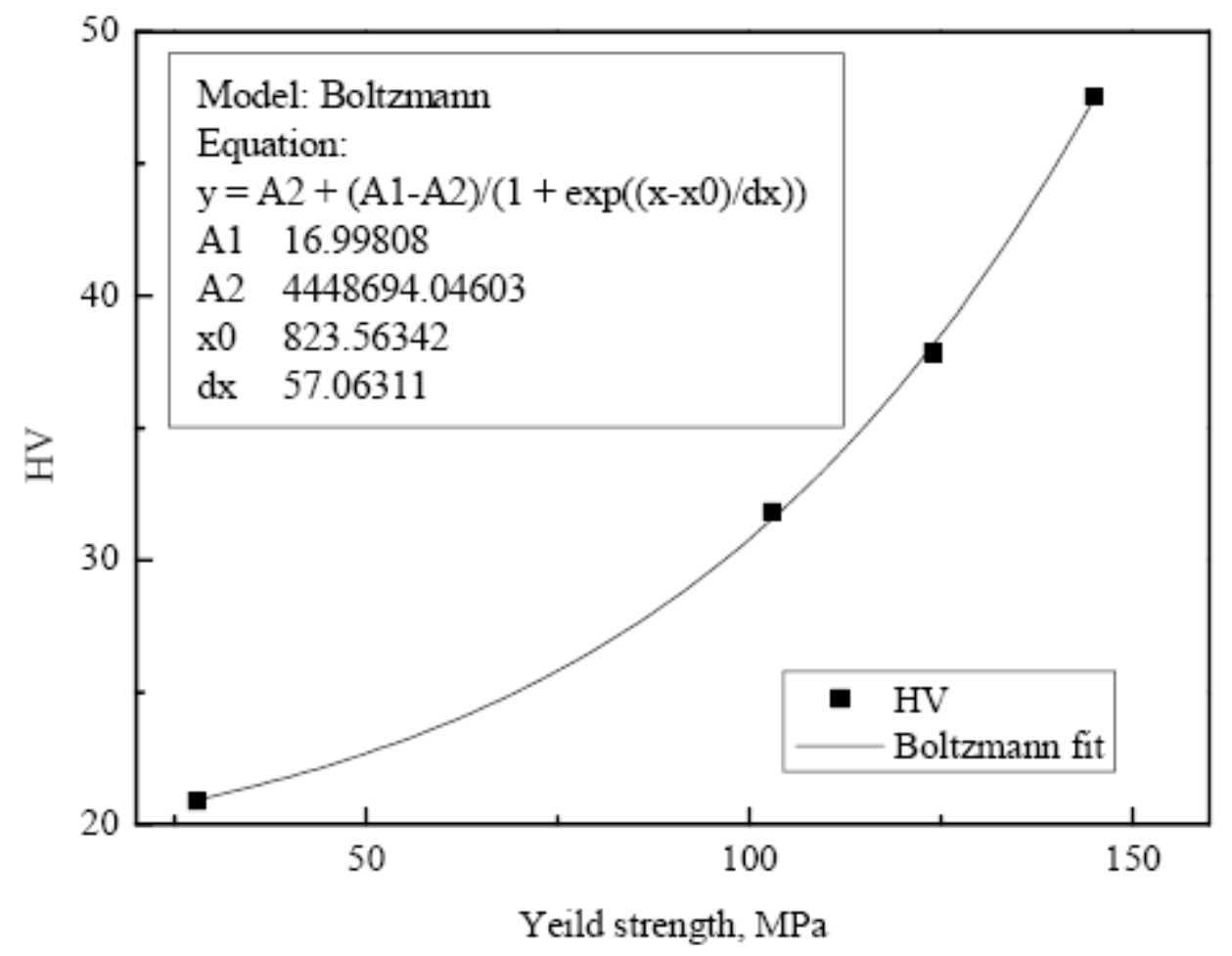

Fig. 5 The relationship between hardness and yield strength of A11050.

\section{Conclusions}

The microhardness on the cross section of the ECAP-processed billet increases from both the top edge and the bottom edge to the centre. The highest average microhardness appears at the centre, which is $48 \mathrm{Hv}$. The average microhardness at the top edge and the bottom edge is $42 \mathrm{Hv}$ and $39 \mathrm{Hv}$, respectively. The average grain sizes of the cross section also increase from both the top edge and the bottom edge to the centre. The average grain size at the centre is $26 \mu \mathrm{m}$. The grain size at the top edge and the bottom edge is $8.2 \mu \mathrm{m}$ and $19 \mu \mathrm{m}$, respectively.

After annealing at $350{ }^{\circ} \mathrm{C}$ for $0.5 \mathrm{~h}$, the billet shows a more homogeneous distribution of microhardness and microstructure. The microhardness at the top edge, the centre and the bottom edge decreased to $26 \mathrm{Hv}, 27 \mathrm{Hv}$ and $27 \mathrm{Hv}$ with average grain sizes of $21 \mu \mathrm{m}, 12 \mu \mathrm{m}$ and $11 \mu \mathrm{m}$.

The contribution of dislocation density to the strength of A11050 after one pass of ECAP is significantly higher than that of grain size. 
A model is described that captures the character of the strengthening mechanism and modelling results fit the experimental results well.

\section{Acknowledgement:}

This work was funded by EPSRC under Grant No. EP/D00313X/1.

\section{References:}

[1] R.Z. Valiev, R.K. Islamgaliev, I.V. Alexandrov, Prog. Mater. Sci. 45 (2000) 103189.

[2] R.Z. Valiev, Y. Estrin, Z. Horita, T.G. Langdon, M.J. Zehetbauer Y.T. Zhu, JOM 58 (2006) 33-39.

[3] R.Z. Valiev, T.G. Langdon, Prog. Mater. Sci. 51 (2006) 881-981.

[4]. C. Xu, M. Furukawa, Z. Horita, T.G. Langdon, Mater. Sci. Eng. A 398 (2005) 66-76.

[5] M. Prell, C. Xu, T. G. Langdon, Mater. Sci. Eng. A 480 (2008) 449-455.

[6] F.J. Humphreys, M. Hatherly, Recrystallization and related annealing phenomena, second ed., Elsevier, Oxford, 2004.

[7] Y. Wu, I. Baker, Scr. Mater. 37 (1997) 437-442.

[8] S.C. Wang, M.J. Starink, N. Gao, X.G. Qiao, C. Xu , T.G. Langdon, Acta Mater. 56 (2008) 3800-3809.

[9] P.B. Prangnell, C. Harris, S.M. Roberts, Scr. Mater. 37 (1997) 983-989.

[10] ASM handbook. Vol. 2, Properties and selection: nonferrous alloys and specialpurpose materials, tenth ed., ASM international. 1991.

[11] M.J. Starink, S.C. Wang, Acta Mater. 51 (2003) 5131-5150.

[12] M.J. Starink, A. Deschamps, S.C. Wang, Scr Mater, 58 (2008) 377-382.

[13] K. Marthinsen, E. Nes, Mater. Sci. Eng. A 234-236 (1997) 1095-1098.

[14] F. Hernández Olivares, J. Gil Sevillano, Acta metall. 35 (1987) 631-641.

[15] E. Nes, T Pettersen, K. Marthinsen, Scr. Mater. 43 (2000) 55-62.

[16] M.F. Ashby, Phil. Mag. 21 (1970) 399-424.

[17] J.R. Kissell, R.L. Ferry, Aluminium structures: a guide to their specifications , design, second ed, John Wiley \& Sons, New York, 2002.

[18] B. Clausen, T. Lorentzen, T. Leffers. Acta Mater. 46 (1998) 3087-3098.

[19] S.G. Chowdhury, A. Mondal, J. Gubicza, G. Krallics, A. Fodor, Mater. Sci. Eng. A 490 (2008) 335-342.

[20] Annual book of ASTM standards, E140-07. Vol 03.01, ASTM (2007).

[21] J. Gubicza, N. Q. Chinh, Gy. Krállics, I. Schiller, T. Ungár, Curr. Appl. Phys. 6 (2006) 194-199.

[22] S.C. Wang, Z. Zhu, M.J. Starink, J. Microscopy 217 (2005) 174-178.

[23] J.R. Bowen, P.B. Prangnell, D. Juul Jensen, N. Hansen, Mater. Sci. Eng. A 387389 (2004) 235-239.

[24] N. Hansen, Scr. Mater. 51 (2004) 801-806.

[25] A.A. Gazder, Wenquan Cao, C.H.J. Davies, E.V. Pereloma, .Mater Sci Eng. A, 497 (2008) 341-352 